\title{
Conceptualizing the transition from education to work as vocational practice: lessons from the UK's creative and cultural sector
}

To be published in the British Educational Research Journal

\begin{abstract}
The paper argues that: (i) the demise of 'occupational' and 'internal' and the spread of 'external' labour markets in growth areas of UK economy such as the creative and cultural $(\mathrm{C} \& C)$ sector, coupled with the massification of higher education which has created a new type of post-degree 'vocational need', means that the transition from education to work should be re-thought as the development of vocational practice rather than the acquisition of qualifications; and, (ii) in order to re-think transition as the development of vocational practice it is necessary to eviscerate the legacy of the 'traditional' conception of practice in UK educational policy. The paper reviews a number of alternative social scientific conceptions of practice, formulates more multi-faceted conceptions of vocational practice, and discusses their implications for UK and EU educational policy.
\end{abstract}




\section{Introduction}

The UK government, like the European Union (EU), assumes that qualifications are a proxy measure for the development of 'vocational practice' (i.e. mix of knowledge, skill and judgement) and that employers can match qualification outcomes un-problematically to occupational profiles (Guile and Okumoto, 2007, page. 559). There are a number of problems associated with policymakers' assumptions and, as we shall see, this necessitate a re-thinking of transition from education to work.

First, despite their rhetoric about the global economy, policymakers do not appear to understand the outcomes of the change in the 'character' of large swathes of work in the global economy (Sennett, 1998; 2005). These changes have occurred in the UK due to the gradual demise of 'occupational' (OLMs) and 'firm-specific' labour markets (FILMS) that characterized post-war national economies and the growth of 'external' (i.e. flexible) labour markets' (ELMs) (Felstead and Jewson, 1999). This is particularly true in the potential highgrowth sectors of the UK economy such as the creative and cultural sector $(\mathrm{C} \& \mathrm{C})$ - Crafts, Design, Fashion, Film, Music, Performing Arts, Publishing, Research and Development, Software, Toys, TV and Radio and Video Games (DCMS, 2001). Historically, FILMs provided a series of job or career ladders to progress within an organization and OLMs enabled new recruits to be trained in a range of occupationally-specific forms of knowledge and skill; ELMs however tend to be contract-based and capital tends to be project-specific (Ashton, 1995). The net effect is, in the case of the $C \& C$ sector, to position aspiring entrants between capital and labour as a freelance cultural 'worker'/'entrepreneur', that is, someone seeking contracts to demonstrate their creative skills and capital to realise their creative ambitions (KEA, 2006, page 91) and, thus, reliant on their own self-generated initiatives to secure employment.

Second, policymakers appear to be unaware that the massification of higher education has created a new post-degree 'vocational need' because although studying for a degree provides a grounding for new entrants to the labour market, it rarely provides an 'expectation or understanding of what was required in vocational contexts' (Raffo et al. 2000, page. 223). The type of vocational experience required to develop such insights and expertise is in the case of sectors characterized by external labour markets, gained through: (i) undertaking un-paid activities such as internships, work placements that offer aspiring entrants opportunities to work with experienced professionals on commercial projects (Galloway et al. 2006); and, (ii) joining network so as to develop a personal occupational labour market to secure contracts or to be invited to contribute to contracts which other freelancers have secured (Raffo et al. 2000; Wittel, 2001). 
UK policymakers continue, however, to misjudge the challenge presented by these labour market conditions and to unequivocally endorse the notion that qualifications constitute a proxy measure for vocational practice, and as such facilitate transition into all sectors of the economy. The most recent example of this article of faith is the draft report circulating from the Department of Culture, Media and Sport The World's Creative Hub (DCMS, 2008). The report argues the Government will help the C\&C sector to realise its perceived economic potential by strengthening the development of 'creative skills' in schools (DCMS, 2008, page. 10) and re-freshing craft skills through an expansion of apprenticeship (ibid, page, 12) and/or through the further development of 'vocational' skills in higher education (ibid, page. 13). Moreover, it concludes that the creation of new 'creative apprenticeships' will 'put an end to the practice of entry-level jobs being unpaid for a period of time' (ibid, page. 14). Thus, the report takes no account of the continuing reluctance of sectors characterised by ELMs and small and medium-sized companies (SMEs) to participate in the Advanced Apprenticeship Programme because of its 'administrative burden' (Fuller and Unwin, 2003, p. 9), or that the growth of unpaid activities in the economy, especially in the $\mathrm{C} \& \mathrm{C}$ sector, is a direct result of families 'financially cushioning' their offspring to assist them to develop vocational practice facilitate their transition into their chosen niche in the $\mathrm{C} \& \mathrm{C}$ labour market (Galloway et al., 2006, p. 52).

The paper argues that fresh thinking is required to address these issues and this entail reconceptualising the transition from education to work as the development of vocational practice, rather than the accumulation of qualifications. The paper tackles this challenge by first explicating, what it refers to as, the 'traditional' conception of practice in philosophy and sociology, and identifying how its legacy in UK educational policy reinforces the idea that qualifications facilitate transition into the labour market. It then reviews some alternative conceptions of practice which have emerged in Socio-Cultural Theory, Science Studies and Activity Theory. Based on this discussion, the paper formulates a number of new conceptions of vocational practice - the evolutionary, laterally-branching and envisioning - and concludes by discussing the implications of this much more multi-faceted conception of practice for UK educational policy and access into the $\mathrm{C} \& \mathrm{C}$ and other sectors of the economy.

\section{The concept of practice and its relation to learning}

\section{The traditional conception of practice and its legacy in UK qualifications}

The concept of practice has a longstanding history in philosophy and sociology and has also 
been the subject of considerable discussion in those fields since the mid 1970s (Bourdieu 1977; de Certeau 1984; Giddens 1984; Pickering 1995; Schatzki et al. 2001). By and large, these conceptions of practice rest on cultural anthropological assumptions about common social patterns of human behaviour. Thus the aforementioned writers tend to emphasis practice's habitual and rule-governed features in specialist field of activity, for example, architecture, that has stipulated standards of performance that are internal to that practice as well as in everyday activities, such as, walking. Though much of the debate is concerned with the specification of the relevant rules and habits through a discussion of the embodied acquisition of preferences, perceptual schemes, dispositions to react and shared tacit rules, most authors seem to agree that 'practices should be seen as recurrent processes governed by specifiable schemata of preferences and prescriptions' (Knorr Cetina 2001, page. 175).

By viewing practices as recurrent processes, philosophers and sociologists tend to level out fluctuations in human activity and diminish any sense of how these events impacts on human behaviour, over emphasising the way in which we are bound to the social world and playing down our scope to generalize about and act with relative autonomy in that world. This trend amongst practice theorists occurs, because to appropriate Alexander's (1995, page. 140) observations about Bourdieu, such concepts of practice do not have:

their own emergent properties, their own logic, their own internal complexity. Because they do not posses any real independence, they cannot provide a vehicle for establishing true micro- macro link ${ }^{1}$.

The absence of any notion of emergent properties has led many practice-based philosophers and sociologist to operate with an implicit conception of learning as a form of 'biologicalised socialization' (Alexander, 1995, page. 144), in other words, an embodied mastering of something that has a stable and well-bounded character which is subsequently deployed or enacted in concrete situations ${ }^{2}$.

The legacy of this philosophical and sociological conventional wisdom extends beyond their overt expression in academic texts and surfaces in the way in which they have influenced commonsense or folk conceptions that practice consists of customary or routinised ways of behaving. These folk notions serve, in turn, as the taken-for-granted assumptions that underpin policymakers' ideas that qualifications constitute a proxy measure for the

\footnotetext{
${ }^{1}$ Alexander's observation refers specifically to Bourdieu's concept of habitus, I have used his generalization to encapsulate a general trend amongst practice theorists.

${ }^{2}$ Alexander (1995, page 144) invokes this term to highlight that Bourdieu's (1990, page 68-9) concept of habituated practical sense is a 'social necessity turned into nature [and] converted into motor schemes and body automaticisms', rather than a cultural process which develops people's ability to interpret other's sensibilities and intensions and act according to reasons.
} 
development of vocational practice. Slightly different manifestations of this idea are found in vocational compared with academic qualifications. In the case of the former, National Vocational Qualifications (NVQs) were explicitly designed on the premise that it was possible to identify 'performance outcomes' based on common, routinised and procedural skills in different work areas and to include them within common NVQ units which, once gained, are applicable in different sectors (Mansfield \& Mitchell, 1996, p. 237). In the case of university degrees, the Dearing Report (NICHE, 1997, page. 14) built the work UDACE (1992) pioneered on the use of 'qualification outcomes' in higher education and proposed that degree programme should stipulate outcomes in the form of 'subject knowledge', 'key' and 'employability' skills to make graduate attainment more transparent, and to enable employers to more easily match their requirements to graduate attainment.

These assumptions about practice and qualification outcomes clearly do not hold within large swathes of the UK economy. Transition into much of the C\&C sector (Raffo et al. 2000; Guile and Okumoto, forthcoming) and also parts of other sectors such as finance (Lundsteen, 2007) increasingly presupposes that aspiring entrants have already developed some experience of working with experienced professionals to bring the particularities of a specific field of practice into a meaningful relationship within the field's commercially established norms or procedures ${ }^{3}$. For example, a forthcoming study (Guile and Okumoto, forthcoming) has highlighted that whereas under-graduates were only expected to produce one new design in six months, jewellery companies expect newly appointed designers to produce over forty designs within six weeks. Opportunities to develop vocational practice in commercial settings are provided to a limited number of graduates and post-graduates through 'sandwich' degrees or the Teaching Company Scheme (Senker and Senker, 1994) in sectors such as hospitality and engineering that are still characterised by internal and firm-specific labour markets. The split between the small number of global corporations and regional clusters of SMEs, freelancers and networks in the $\mathrm{C} \& \mathrm{C}$ sector, however, makes it harder to provide equivalent schemes and experiences (Guile and Okumoto, forthcoming). While the lack of a 'language of description' (Daniels, 2004), that is, a way of distinguishing between different purposes for and outcomes of practice makes it difficult to capture the developmental nature of the working/learning experience. The former issue is returned to later in the paper, the first task is to develop a more multi-faceted conception of vocational practice.

\section{The quasi-natural genesis of practice: intra-community mediation}

\footnotetext{
${ }^{3}$ Bourdieu (1966) defines his concept of field in 'relational' terms. He explains what is distinctive about one cultural field compared with another by focusing on competition within and between fields. My use of the term retains his relational dimension, however, in recognition of the process of 'convergence' occurring in the $\mathrm{C} \& \mathrm{C}$ sector (Bilton 2006; Florida 2002) it is less concerned with competition between fields and focuses more on intra-and inter-development of cultural fields.
} 
One of the most powerful influences on the research community's thinking as regards practice and learning in the last two decades is Lave and Wenger's (1991) book Situated Learning. Lave and Wenger's text also rests on cultural anthropological assumptions about the commonalities between practices, however, their work differs in one significant respect from the philosophical and sociological conceptions of practice. Lave and Wenger supplement their concern for social order with a social psychological concern for the inter-subjective basis of human development and hence the relation between practice, learning and identity. This leads them to define learning in developmental terms as 'changing participation in changing practice' and, in the process, to highlight practice's generative purpose.

\footnotetext{
Learning, transformation and change are always implicated in one another, and the status quo needs as much change and explanation. Indeed, we must not forget that communities of practice are engaged in the generative process of producing their own future (Lave and Wenger 1991, page. 56-7).
}

Thus Lave and Wenger (1991, page. 97) broaden the behavioral notions about practice's rulegoverned character that characterise much philosophy and sociology by acknowledging its emergent possibilities. Thus, they conceptualise practice as a triangular mediated relation between people, tools and context that evolves as a result of tensions between 'old timers' and 'newcomers' (i.e. legitimate peripheral participants) with the result that and new forms of knowing and learning are constituted (Arnsneth, forthcoming). For this possibility to be realised newcomers require access through a 'learning curriculum' to the 'technologies of practice' (page. 101), that is, the tools, protocols, procedures etc, that experienced members of a community use to develop the embodied forms of knowledge, skill and judgement associated with a particular practice and the requisite vocational identity. And having done so, to identify the way in which the technologies or the practices are in need of revision, and work collaboratively with or clash with old-timers as regards the development of practice and its technologies.

Lave and Wenger's focus on the contested nature of inter-subjective relationships results in a slightly one-sided conception of practice's generative basis, because it precludes, as Billett et al. (2004) observes, any sense that people evolve practice under less fraught circumstances and through their own volition. Billett (2003, page. 12) explores this issue through his notion of 'relational interdependence', that is, individual engagement with workplace cultural practice. Billett et al. (2004, page. 220) argues that it is the interplay between 'agentic' activity and contextual 'affordance' that facilitates the 'remaking' of workplace practice. 
interactions, and through intentional learning strategies are those associated with the degree of affordance (e.g. support, opportunities, interactions, guidance) provided by the workplace, and also the degree and bases by which individual engage in the workplace.

Thus Billett, like Lave and Wenger, adopts an anthropological or quasi-natural perspective on learning and maintains that individuals learn as they participate in workplace practices. Where he differs from them is in making in the development of personal identity more explicit and drawing attention to the continual remaking of cultural practices. The forms of remaking that Billett (2004) identifies in the fields he has studied, for example, IT helpdesks, fire station, gymnasium and restaurant, are primarily ontogenetic and microgenetic; they result primarily in changes of practice at the individual rather than the sociocultural level and thus rarely have implications for the wider practice field.

In highlighting the relational, embodied and situated basis of practice, Billett and Lave and Wenger reveal the social intertwining of practice and learning that the philosophers and sociologists overlooked: people learn as they engage with pre-given pedagogic conditions (i.e. legitimate peripheral participation) and/or perceive affordances in the environment and use collective and/or individual agentic activity to evolve practice. Thus, they bring the generative basis of practice based on human ingenuity to the fore. Lave and Wenger and Billett ideas about the generative basis of practice, however, play down the epistemic and symbolic character of some forms of practice. This issue has recently been addressed by Karen Knorr Cetina, and her work, as we shall see, provides another angle on the concept of practice and its link to learning.

\section{The epistemic genesis of practice: intra-professional mediation}

Knorr-Cetina (2001, page. 177) makes a two-fold argument about knowledge societies and practice. First, that the transition to a knowledge society presupposes not only the presence of more experts, more technological gadgets, more specialists rather than participant interpretations, but also the existence of 'epistemic practice' (i.e. knowledge-generating processes). Second, that although epistemic practices have traditionally been associated with science, scientists' knowledge generating practices, for example, the accumulation, verification and distribution of knowledge to remediate practice, are becoming a constitutive feature of other professions ${ }^{4}$. Thus, for Knorr Cetina' (p. 175), if more occupations and organizations have a significant knowledge base:

\footnotetext{
${ }^{4}$ Some of the writers discussed in the paper, for example, Knorr Cetina use the term professional rather than vocational when addressing the knowledge, skill and judgment associated with particular fields of practice. To avoid doing violence to their arguments I have retained their preferred terminology and endeavoured to show how their insights allowed me to develop the conception of vocational practice formulated in the paper.
} 
one would expect practitioners to have to keep learning, and the specialists who develop the knowledge base to continually reinvent their own practices of acquiring knowledge, Practice, in this case, would seem to take on a wholly different set of meanings and raise a different set off questions from the ones raised by habitual activities.

The hallmark of epistemic practice is, according to Knorr Cetina (2001, page. 158), its 'relational dynamic' and capacity to 'laterally branch out'. This branching out only happens, however, if practitioners first, view the objects of practice, for example, concepts, protocols, technological resources, as having an open, question-generating and complex character, rather than the closed and taken-for-granted character redolent of the objects in routinised conceptions of practice. Second, actively disseminate the forms of knowledge they produce through their professional activities so its productive efficacy is made apparent beyond its immediate context of production and application.

Knorr Cetina (Breugger and Knorr Cetina 2000, page. 5) illustrates the way in which this question-generating character manifests itself in fields other than science. She points out that processes of inquiry in the open-textured character of many situations that emerge in the knowledge economy, where it is impossible to resolve dilemmas through recourse to existing routine and schemas which have usually been devised with 'the most part only' of wellknown situations in mind, rarely come to a natural end where everything worth knowing about an object has been established; thus they 'leave practitioners with a continually renewed interest in knowing that is rarely fulfilled by final knowledge' (Knorr Cetina 2001, page. 186).

To facilitate the branching out of practice, practitioners turn to concepts, objects and practices that lie outside the immediate context, and use them as resources to re-think and re-configure their practice and its field by engaging in a form of 'combinatorial creativity' (Vygotsky 2004, page. 9), that is, articulating to one another why and how to make illuminating connections between concepts, objects and practice to address current professional challenges. This combinatorial activity presupposes the continued development of, refinement of and application of exercise of judgement ${ }^{5}$. Thus as professionals focus and progressively refocus their attention to gain a measure of control over the materials they are using, a greater sense of the relevance of the expertise held by other professionals they are working with proximally

\footnotetext{
${ }^{5}$ My ideas about the role of judgement as an integral feature of the concept of vocational practice have been heavily influenced by Joseph Dunne's book Back to the Rough Ground (1993). Like Dunne, I accept that it is a futile exercise to disembed the knowledge and skill integral to practice and to try to encapsulate them in explicit, generalizable formulae, procedures or rules. Where we differ is that Dunne is explicitly interested in recovering Aristotle's concept of phronesis in order to articulate what is distinctive about the relationship between judgement and practice in the modern age, whereas I have a much more circumscribed aim to acknowledge that judgement is an integral aspect of any form of vocational practice.
} 
or distally emerges, and they gradually develop the forms of judgement which enable them to produce an imaginative solution to the problem in hand.

Knorr Cetina articulates a conceptualization of practice which reflects her understanding of the implications of the shift towards a knowledge-based society: practice is intentional and prospective (i.e. concerned with the here and now and the future) epistemically-mediated through the use of resources which are external to its context. She nevertheless leaves us with a binary notion of practice: a rule-governed and routinised conception seemingly impervious to development; and, a knowledge-based, unfolding and lateral branching conception. Given Knorr Cetina's starting point in sociological debates about knowledge societies, this counterposing of traditional and epistemic conceptions of practice is understandable. In relation to the concern of this article her binary conception is unhelpful: it is insufficiently nuanced to acknowledge the generative basis of practice; and, it rests on a rather underdeveloped sense of the mediated relation between epistemic objects and practice.

The root of epistemic practice and the way it positions people to turn to the objects of their own or other practice as a resource for professional learning has recently been explored by a number of writers. Jensen and Lahn (2005) have extended and elaborated the implications of Knorr Cetina's argument by identifying the way in which the attachment formed during initial professional formation to the knowledge associated with a field of practice, constitutes the resource for the subsequent development of practice and the field. They argue that professionals in the fields that they have studied - accountancy, engineering, nursing and teaching - are actively involved with the continual unfolding of professional practice (Jensen and Lahn 2005, page. 318) - and as a consequence continually renewing and revitalizing themselves and their field of practice. The seeds of this renewal are sown during initial professional formation as practitioners participate in a multifaceted learning process that consists of programmes of professional development designed and facilitated by universities or professional associations, self-generated learning activities based on engagement with theoretical and practitioner literature available through libraries and via the Internet, and participation in professional e-discussion communities, and enculturation in workplace practice. This combination of guided and self-directed support allows, as Jensen and Lahn note (2005, page. 318$)$, practitioners to gradually:

\footnotetext{
begin to appreciate that all is not fixed, shared, finished and complete: there is always a new and unexplored possibility. This recognition paves the way for a dynamic openness - an experimental mentalite'.
}

Such a mentalite' enables practitioners to escape from the immediacy of a particular time and 
place which can leave them overly reliant on local and insular forms of conventional wisdom. As a consequence, practitioners become 'anchored in symbols and ideas rather than the immediacy of a particular place or time' (page. 318). This anchoring serves two purposes: practitioners have contact with new theoretical concepts or form of epistemic practice which lie beyond their immediate context and, as a result, they are brought into contact with the complexities involved in rendering meaning to their specific field. Jensen and Lahn (2005, page. 318) describe the distinctive character of the mediated process between concepts, practice and the development of judgement and a capacity to act as:

a back-and-forth looping process between traditional meanings and more current impulses the students modernize the concept of care and also recharge the field with normative meaning.

By this they mean, the ability to use the generalization(s) contained in a theoretical concept as a source of enrichment of what is immediately given through perception or is the taken-forgranted conventional wisdom about practice and, as a result, to identify possible courses of action to remediate practice.

In contrast, Nerland explores how experimental mentalites' formed through immersion in knowledge traditions are developed through work-based learning. Nerland (2008, page, 53) makes a two-fold argument: 'professional knowledge cultures are collective mentalities that both express themselves in certain practices' because the organisation of knowledge associated with those cultures is related to specific 'styles of reasoning, believing and acting'; and, that the forms of work-based learning in which practitioners engage are always characterised by a tension between the regulative (i.e. adherence to standards) and agentic (i.e. practitioners' relation to knowledge and knowledge objects). This tension manifests itself because although engineers typically go about:

making up scenarios about things and principles, physical concepts and variables and how they relate". However, while such activities require creativity, the aim of the scenario making is to achieve a closure by arriving at a solution that is "fixed, repeatable, stable, unambiguous, and internally consistent" (ibid, p. 212). Thus, there is a paradox between the specified and the ambiguous in this knowledge domain, where the practitioner becomes involved in learning by constantly moving between the unfulfilled and the temporarily fixed (page, 61).

Focusing on engineer's work-based learning, Nerland points out that the way in which engineers are positioned to learn in their company and in their professional community helps them to consecrate their professional reputation and to support their company to thrive in the highly competitive global knowledge economy. She reveals that the precise character of 
engineers' learning is shaped by the opportunities that are officially sanctioned by their firm or that the engineer's create for themselves through their own agentic activity to 'play' with different software programmes. The learn, in other words, to innovate by modifying and/or radically transforming software programmes and subsequently publicizing these developments via the internet to the global engineering community. The net effect is a virtuous cycle: firms increase their competitive advantage, engineers increase their employment prospects and the wider field is enriched.

Taken in combination, Jensen, Lahn and Nerland shed light on a number of issues that remain a taken-for-granted feature of Knorr Cetina's work. They highlight that the mediated relation between professional education, access to knowledge objects, creative engagement with practice and organised dissemination channels, constitutes the normative conditions for not only professional learning, but also for the development of a field of practice nationally and internationally. In the case of the former, their argument that the outcome of professional and work-based formation is the development of an experimental mentalite' provides a counter to the post-Rylean tendency in professional education, vocational education and work-based learning, for example, Schon (1978), Eraut (1995) and Beckett and Hager (2001) to assume that education develops 'know what' knowledge and work practice develops 'know how' knowledge. In contrast, Jensen, Lahn and Nerland add another dimension to Toulmin's (1974) argument about the interrelationship between theory and practice in different professional communities by revealing the way in which immersion in knowledge/professional domains develops styles of reasoning which influence the way in which we participate in and make judgements about practice. In the case of the latter, the focus on professionally sponsored and organised dissemination channels offers empirical substance to Knorr Cetina's arguments about the spread of epistemic cultures in fields other than science.

Jensen et al., like Knorr Cetina, however, concentrate on intra-professional practice. The growing tendency in modern societies for inter-professional collaboration and professionalconsumer collaboration so as to 'co-create' new products and services that will appeal to culturally diverse customers in global markets, (Thrift 2006) is, however, introducing radically new dimensions to practice. This generates a new conceptual problem for practitioners - how to mediate between different epistemic traditions - and in order to consider how address this issue, it is helpful to turn to the work of Yrjö Engeström.

\section{The epistemic genesis of practice: inter-professional mediation}

In contrast to situated theorists who are concerned with meaning making and theorists in science studies such as Knorr Cetina who are concerned with the largely unknown effect of working with epistemic artifacts, Engeström (1999; 2001) writes from the perspective of 
activity theory. Thus, he focuses on the 'object of activity', that is, the mediated relation between the social purpose and organisation of an activity such as the provision of health care, and the individual and collective motives for engaging with and the outcomes from that engagement (2001, page. 8). This focus on the purpose of, organisation of, and resources for, activity provides a way to analyse inter-professional activity and, as we shall see, allows us to broaden Knorr Cetina and Jensen at al.'s concept of epistemic practice and learning ${ }^{6}$.

Professionals in modern societies and organizations (in his terms an 'activity system'), are, according to Engeström (2004, page. 150), increasingly forced to collaborate because such systems are characterized by contradictions:

\begin{abstract}
that is historically accumulating structural tensions within and between activity systems. The activity system is constantly working through tensions and contradictions within and between its elements. Contradictions manifest themselves in disturbances and innovative solutions. In this sense, an activity system is a virtual disturbance- and innovation-producing machine.
\end{abstract}

These contradictions emerge in activity systems as individual participants begin to question and deviate from established norms. Engeström maintains, however, that providing members of those systems have access to forms of pedagogic support which will enable them to rethink or 'expand' the object of activity (page, 150), they are able, in principle, to transform an activity system.

To do so, Engeström $(2007,364)$ has developed a set of concepts and a methodological approach based on Vygotsky's notion of 'dual simulation'. This involves placing members of individual or networks of activity systems in a structured situation to address a problem and providing them with resources and guidance to expand the object of activity and to re-design their system(s) to reflect the new object. The main feature of the methodology are that members of an activity system(s): (i) work in partnership with researchers in a specially designated space - a 'boundary-crossing laboratory' - which is established inside an activity system; and (ii) use the 'cycle of expansive learning' (CEL) - the pedagogic process which Engeström (2004, page. 155) has devised - to enable them to induce change in such systems by envisioning a new object of activity. This process is predicated on the principle of 'separation and embeddedness' (page, 372): members from an activity system(s) work together away from their daily practice to problematise the material and symbolic boundaries which engulf their practice (page, 156-7) and collectively consider how to transform those practices; and then reflect critically on the emerging suggestion when they return to their

\footnotetext{
${ }^{6}$ Having clarified the similarity and difference between the concept of practice and 'practical object related activity' in Activity Theory, the discussion of Engeström uses the latter term to do justice to his position.
} 
normal daily routines.

The concept of the object of activity and the CEL offer a different starting point for considering the epistemic basis of practice compared with Jensen and Lahn's focus on immersion in disciplinary traditions. It alerts us to the importance of identifying a framework to support heterogeneous communities, whose vocational formation and workplace experience may have led them to reason and act in different ways from one another, to question the existing principles for, the motives behind and the form of organization that underlies, accepted practice in an activity system (page, 151). The outcome of this mediated epistemic, as Engeström (page. 91) observes, is:

a reconceptualisation of the object and motive of the activity so as to embrace a radically wider horizon of possibilities than in the previous mode of the activity.

This reconceptualisation is normally expressed in the form of a new concept which members of an activity system then use to identify the new practices required to realize the new vision. Engeström's (2001) best-known example is the 'care agreement' which was used to reconfigure the rules, community and division of labour in parts of the Finnish Health Service to provide a more holistic form of care. He describes this type of new concept as 'epistemically-grasped practice' (page. 151), in other words, the concept was formed through participation in a process where the new concepts' meaning gradually unfolded as members used his battery of concepts to analyse the implications of the new concept for their own practice, its relationship to other practices and hence to the collective object of activity. For example, as doctors, nurses, patients etc contributed through dialogue and debate to the implementation of the care agreement, the doctors and nurses agreed to transform the existing division of labour, to revise the rules that underpinned the professional-client relation and to broaden the constituency whose views and opinions should be considered when planning and organizing health care in future.

Interpreted at its broadest, Engeström helps us to understand the challenges that interprofessional communities face if they are to create new contexts for practice and new artefacts. The first challenge is to create the pedagogic conditions to reposition members of activity system(s) in relation to their current object of activity so that they are 'freed-up' to think afresh about their object of activity, in other words, do not cling to profession-specific styles of reasoning, believing and acting, and to agree a new way to realise that activity. The second challenge is to support people over an extended time frame to identify both the implications of their suggestions for the organisation of work, inter-professional relations and so forth, and to work collaboratively to then reconfigure the institutional and professional 
boundaries of their different but related practice.

Engeström has primarily concentrated on re-thinking practice within and between institutions, for example, banks, hospitals, schools, which have well-established divisions of labour, rules and communities. The pattern of work has, however, been changing in the public and private sectors in advanced industrial societies for many years. Downsizing and out-sourcing, coupled with the rapid growth of SMEs, freelance work, has over the last decade had paradoxical outcome: it has contributed to the erosion of the 'character' of work and workers identity in many sectors, (Sennett, 2000) and created a much more fluid and dispersed business context for other sectors (Thrift 2003), especially the creative and cultural sector (Bilton 2006), where people seem to thrive on working in temporary teams that come together only for the life of a project (Caves , 2000).

It is difficult, if not impossible, in these circumstances to establish a boundary crossing laboratory because work is distributed over a mix of 'traditional' (i.e. offices) and 'new' (i.e. coffee shops) sites. Nevertheless, the concept of the object of activity can be used to analyse the formulation (i.e. figuring out) and instantiation (i.e. negotiating the work process) of new artefacts and practice in this type of work context. Guile (2007) has shown how a network consisting of artists, architects, structural engineers, landscape gardeners, representatives from a local council and local industry, who had never previously worked together, formulated the purpose of and instantiated to realise a new artefact. His argument in a nutshell is that the interplay between two forms of project-generated expertise - 'epistemic' and 'pedagogic' - expertise - is central to the creative process. The former refers to the various kinds of knowledge, skill and social functions which have to be built into a new artefact in such a way that they are aligned and coordinated to make the new artefact functionally coherent and representative of all parties' desires and interests. The latter to the relationships that have to be collaboratively established between all parties and continually renewed throughout the life of the project, so they are able to bring their expertise to bear on the formulation and instantiation of the new artefact. This interplay is vital because contributing parties inevitably put forward competing and contending ideas as regards the design of the artefact, technical suggestions to realise the design, different views about the likely outcome of one another's suggestion and different views about the proposed working methods.

Given that participants rarely have a history of working together which might offer some continuity to their work practice, they are faced with the challenge of learning how to grasp the implications of new ideas and suggestions as well as how to respond to them. Guile identified that the participants accomplished this goal by: (i) asking questions that probed the 
reasons behind team members suggestions/opinions; (ii) ensuring that responses built upon views/ideas offered; and (iii) using their emerging knowledge of those reasons to infer what might or might not follow in relation to the project in hand. He invoked the concept of the 'space of reasons' to highlight that it was only as participants engaged in the above processes that they were able to grasp the system of mediating connections that informed one another's concepts, practices and judgements, that is, make explicit to one another what was implicit in their beliefs and actions, and work successfully work together to instantiate the new artefact (Guile, 2007, page, 250 ).

The concept of the space of reasons offers another angle on the challenges that heterogeneous communities face if they are to formulate and instantiate new practice and artefacts. It allows us to see that, on the one hand, the creative process flourishes when heterogeneous project teams recognise that the reconciliation of competing suggestions is a normal rather than an exceptional feature of work; and, on the other hand, the resolution of such suggestions entails collectively agreeing which reasons are more significant than others in particular situations and results in a certain course of action being adopted and certain artefacts employed in particular ways. Thus it allows us to appreciate the way in which project-teams can, providing they adhere to the above pedagogic principles, self-generate new form of knowledge and practice.

\section{Reconceptualising vocational practice}

\section{New conceptions of vocational practice}

Based on the above discussion it is possible to derive a number of new conceptions of vocational practice that are analytically distinct from one another because each one rests on a different idea about the generative basis of practice, yet related because they are predicated on an acceptance of the embodied, relational and situated character of practice. The conceptions are the:

- evolutionary conception of vocational practice;

This conception represents a combination of Billett and Lave and Wenger's ideas about the generative, embodied, relational and situated character of practice. Thus it assumes that: (i) we are sapient creatures who use our ingenuity to constantly modify, vary and reassemble practice; (ii) workplace pedagogies are central to the development of vocational practice; and (iii) learning presupposes individual and/or collective agentic activity. 
- laterally-branching conception of vocational practice;

This conception is based on Knorr Cetina's and Jensen and colleagues' ideas about the epistemically-incomplete nature of and epistemically-mediated development of practice. Thus, it offers a different angle on the generative, embodied, relational and situated character of practice because it explicitly recognises that: (i) practice fields develop different embodied ways of reasoning and acting in the world; (ii) epistemic resources associated with and/or lying outside of the immediate context are central to the remediation of practice and the field; and, (iii) reasoning and acting in homogeneous fields of practice presuppose a process of conceptual restructuring (i.e. thinking differently about the object of activity in relation to the norms of the field) and repositioning (i.e. considering possibilities for action and their implications for the development of the norms of the field).

- envisioning conception of vocational practice.

This conception builds upon the former by incorporating Engeström's and Guile's ideas about the way in which heterogeneous communities learn to reconfigure and/or create new objects and practices. Thus it assumes that: (i) heterogeneous communities are characterised by a multitude of different embodied ways of reasoning and acting; (ii) reasoning and acting in such communities presupposes re-thinking the object of activity by locating other people's ideas/suggestions in the space of reasons, and inferring and agreeing what follows from these often competing suggestions in relation to the creation of new artefacts/practices; and (iii) the remediation and/or creation of new practices and objects pre-supposes internally-generated or the recruitment of externally-devised pedagogic methodologies and strategies.

\section{Transition as vocational practice: issues for research and policy}

In addition to providing a new language of description - evolutionary, laterally-branching and envisioning - for practice that allows us to distinguish between different expressions of creativity within, resources for, and outcomes from practice, the new conceptions also have significant implications for research into and policy for transition into the labour market.

In the case of the former, they offer us a way to go beyond the recent debate between the 'front-loaded' (Winch and Clarke, 2004) and the 'practice-based' (Hager, 2006) debate about the role of education in supporting the transition from education to work. This debate hinges on a difference of view between Winch and Clarke and Hager as to whether it is essential for people to undertake a period of formal education that offers conceptual breadth and occupation-specific training before they can be regarded as a qualified worker, or whether the 
emergence of less occupationally-specific forms of work means that knowledge and skill is best acquired through a combination of work-based learning supplemented by some form of generic skills training. The problem with this debate in relation to the argument presented in this paper is that: on the one hand, Winch and Clarke's argument is too nostalgic about the labour market (i.e. assumes the continued presence of OLMs and FILMs) and too narrow as regards vocational practice (i.e. assumes that occupations are characterised by clearly defined work roles and tasks and that practice consists of the constant rehearsing of pre-given rules or procedures in a workplace); and, on the other hand, Hager's argument is too accepting of the rhetoric of post-modern versions of the knowledge economy that stress the demise of occupations and occupational boundaries and the rising demand for generic skills.

In contrast, the argument presented in this paper is based on a more nuanced analysis of the character of and the nature of transition into the labour market, and an iterative conception of the relation between theory and practice. In the case of the former, the paper has highlighted that the growth of ELMs is creating a new type of post-degree vocational need - opportunities to develop the three expressions of vocational practice - and that policymakers appear to be oblivious to this development. In the case of the latter, although the paper accepts Winch and Clarke's premise that the forms of knowledge made available through formal education constitute a resource for vocational practice, it follows Jensen at al. and conceives of the outcome of vocational formation as the development of an experimental mentalite', rather than as the acquisition of a fixed knowledge base that is then somehow applied in practice. This suggests that what is required is a less linear and a more iterative conception of vocational formation. This conception would assume that everything is not fixed or predetermined within a field of practice, and that people should be supported to develop a sense of inquisitiveness so as to identify problems and identify the appropriate epistemic resources and objects to solve those problems.

Furthermore, although the paper accepts Hager's premise that the context of work has changed and that people can learn valuable aspects of practice in the workplace that can never be replicated in formal education, it does not abandon the notion of an occupation, occupational identity and occupationally-specific knowledge and skill. From this perspective, generic skills such as team working are not context-free skills (i.e. occupationally nonspecific), rather they are rooted in accordance with the normative conventions that underpin the styles of thinking, reasoning and acting associated with a particular vocational field. Thus it follows that although academic and vocational programmes of study at any level can provide a grounding and inspiration for learners, they are unlikely to provide the conditions to develop vocational practice. This requires opportunities to work in a commercial environment with vocational communities who laterally branching out or re-envision their practice. 
Taken in combination, the above observations raise a new question for policymakers: how to support aspiring entrants to develop vocational practice to assist them to enter ELMs? Some insights into this question have been provided by The Last Mile - a multi-partner intervention project funded through the EU's EQUAL Programme looking at inclusion and learning in the creative and cultural sectors in the following regions in the UK: Cumbria, London, Birmingham, Manchester, Sheffield, Slough, with special reference to the Black and Minority Ethnic population. The Last Mile has differentiated between the contribution that three strands of activity make to the development of vocational practice in ELMs:

- the accredited strand - participation in an academic/vocational programme that provides the grounding in the domain knowledge associated with a field and begins to develop an experimental mentalite';

- the industry-recognised strand - participation in non-accredited activities such as work placements, internships, master classes provided by employers to develop the styles of reasoning and acting in accordance with the norms of a vocational field;

- the network strand - participation in networks to develop a personal occupational labour market as the basis of securing contracts in ELMs.

These analytical distinctions reveal the different, albeit, related contribution each strand makes to the development of vocational practice and hence transition into the labour market. With respect to the vexed question of how to persuade employers to work in partnership with education to facilitate transition in the $\mathrm{C} \& \mathrm{C}$ labour market, The Last Mile has shown that 'intermediary agencies' are a particularly effective mechanism to co-ordinate the market and to persuade employers to offer work placements and internships and to run master classes (Guile, 2006). This term refers to the range of agencies that act as catalysts to bring corporations, SMEs, freelancers and networks together to offer aspiring entrants access to work placements and networks. Intermediaries are found in the formal education sector (i.e. education-industry liaison units in universities), the not-for-profit sector (i.e. SMEs specializing in project management) and the non-formal sector (community arts organizations), and they specialise in securing funds from sources such as the European Union, UK government departments, charitable foundations and the private sector to: (i) deliver courses that are not necessarily tied to a recognized qualification; (ii) arrange internships/work placements for aspirant entrants with experienced practitioners and/or companies; and (iii) run events to strengthen fledgling networks and partnerships. 
SMEs, freelancers and networks are prepared to run master classes and offer internship and/or work placements because these activities provide them with a small additional income stream and an additional source of labour to help them to develop their own businesses (Guile, 2006). Equally, aspiring entrants are prepared to participate in such un-paid activities because they offer them an opportunity to, on the one hand, work in contexts where they can begin to engage with the expressions of vocational practice identified in the paper and, on the other hand, develop a reputation in their chosen vocational field and contacts to assist them to secure contracts for their creative services (Guile \& Okumoto, 2007; forthcoming).

Taking the separate but linked lines of argument presented in this paper in combination, it follows that it is no longer helpful to conceive of transition as the accumulation of qualifications and should instead be seen as the development of vocational practice. To enact the implications of this shift in focus, it will be necessary for policymakers to:

- acknowledge the different contributions that accredited, industry-recognised and networked strands of activity make to the development of vocational practice;

- devolve for funding these strands of activity to regional stakeholders so they can design bespoke solutions for their skill needs

\section{Conclusion}

The paper has made a two-fold argument. First, that the demise of OLMs and FILMs and the spread of ELMs in the growth areas of UK economy such as the C\&C sector, coupled with the massification of higher education which has resulted in more graduates needing to develop their vocational practice, means that the transition from education to work should no longer be conceived as the accumulation of qualifications and instead should be re-thought as the development of vocational practice. Second, that re-thinking transition as the development of vocational practice presupposes the replacement of routinised with more multi-faceted conception of vocational practice in UK educational policy. To this effect, the paper has formulated a new language of description for vocational practice - evolutionary, laterallybranching and envisioning - argued that these new conceptions capture the different modalities of practice and the forms of working and learning required to develop them, and identified a number of strategies to support aspiring entrants to develop these different modes of vocational practice.

The re-thinking of the relationship between vocational practice, qualifications and transition into the labour market is particularly timely. The introduction of the European Qualification Framework (EQF) has resulted in educational institutions attempting to standardise 
qualifications throughout Europe through the use of programme specifications and learning outcomes. This development is likely to re-affirm the idea pan-Europe that qualifications constitute a proxy measure for vocational practice. This is deeply worrying because, as Richard Sennett (2008a) has most eloquently argued, the knowledge associated with any 'craft' (i.e. field of vocational practice) is always broader than any qualification and requires opportunities for people to 'conduct inquiries' and not 'rehearse procedures'. Hopefully, the formulation of a new language of description for vocational practice in this paper will offer researchers, policymakers and practitioners a resource to develop new strategic partnerships to support aspiring entrants to make more effective transitions into the labour market.

\section{Acknowledgements}

I would like to thank Monica Nerland for her comments on an early draft of the paper and for inviting me to present the paper at a seminar in the Faculty of Education and Social Research, University of Oslo, 16th March 2007, and to express my gratitude to my discussants Hans-Christian Arnsneth and Terje Gronning for their helpful comments. In addition, I would like to thank Michael Young, Lorna Unwin and my two peer reviewers for their comments which helped me to further revise the paper.

\section{References}

Alexander, J. (1995) Fin de siècle social theory: relativism, reduction, and the problem of reason (Verso, London).

Arsneth, H-C. (forthcoming) A critical account of the concepts of practice and situatedness in relation to activity theory and Lave and Wenger's 'situated learning' - with special relevance to educational research

Ashton, D. (1993) Understanding change in youth labour markets: a conceptual framework, Journal of Education and Work, 6(3), 5-23.

Beckett, D. \& Hager, P. (2002) Life, Work and Learning: Practice in Postmodernity, (Routledge, London).

Billett, S. (2003) Vocational curriculum and pedagogy: an activity theory perspective European Educational Research Journal, 2(1), 6-21

Billett, S., Smith, R \& Barker, M. (2005) Understanding work, learning and the remaking of cultural practices. Studies in Continuing Education 27 (3) 219-237

Bilton, C. (2007) Management and creativity: from creative industries to creative management (Oxford, Blackwell Publishing).

Bourdieu, P. (1977) The Logic of Practice (London, Polity Press). 
Brown, P. (2006) The opportunity trap: education and employment in a global economy, Lauder, H., Brown, P., Dillsbough, J-A., and Halsey. A.H.Education, Globalisation \& Social Change. Oxford: OUP

Caves, R. (2000) Creative Industries: Contacts between Art and Industry Harvard: Harvard Press

Daniels, H. (2006) Analysing institutional effects in Activity Theory: First steps in the development of a language of description Outlines Vol 2 No 1 43-58

DCMS (2001) The creative industries mapping document 2001. Available online at: http://www.culture.gov.uk/global/publications/archive_2001/ci_mapping_doc_2001. htm (accessed 13 July 2007).

DCMS (forthcoming) The World's Creative Hub London: HMSO/Department of Culture, Media and Sport,

De Certeau, M. (1984) The practice of everyday life (Berkeley, University of California Press).

Dreyfus, H. \& Dreyfus, S. (1986) Mind over machine (Oxford, Blackwell).

Dunne, J. (1993) Back to the rough ground (Paris, University of Notre Dame Press).

Edwards, A. (2004) Let's get beyond community and practice: the many meanings of learning by participating, The Curriculum Journal, 16 (1), 49-65

Engeström, Y. (1987) Learning by expanding: an activity-theoretical approach to developmental research (Helsinki, University of Finland).

Engeström, Y. (1999) Activity theory and individual and social transformation, in: Y. Engeström, R. Miettinen \& R-L. Punamaki (Eds.) Perspectives on activity theory (Cambridge, Cambridge University Press).

Engeström, Y. (2004) The new generation of expertise: seven theses, in: H. Rainbird, A. Fuller \& A. Munro (Eds.) Workplace learning in context (London, Taylor Francis).

Engeström, Y. (1987) Learning by expanding: an activity-theoretical approach to developmental research (Helsinki, University of Finland).

Engeström, Y. (2007) Putting Vygotsky to Work: the Change Laboratory as an Application of Double Stimulation in: H. Daniels, M. Cole \& J. Wertsch (Eds.) The Cambridge Companion to Vygotsky (Cambridge, Cambridge University Press).

Felstead, A. \& Jewson, N. (1999) (eds) Global Trends in Flexible Labour, Basingstoke: Macmillan.

Florida, R. (2002) The rise of the creative class (New York, Basic Books).

Fuller, A. \& Unwin, L. (2003a) Creating a 'Modern Apprenticeship': a critique of the UK's multi-sector, social inclusion approach, Journal of Education and Work, 16(1), 5-25.

Fuller, A. \& Unwin, L. (2003b) Learning as apprentices in the contemporary UK workplace: creating and managing expansive and restrictive participation, Journal of Education and Work, 16(4), 407-426.

Giddens, A. (1984) The constitution of society: outline of the theory of structuration (Oxford, Polity).

Grabher, G. (2001) 'Ecologies of creativty': the village, the group and the heterarchic organization of the British Advertising Industry, Environment \& Planning, 33(2), 351-374.

Guile, D. (2006) Access, learning and development in the creative and cultural sector: from 'creative apprenticeship' to 'being apprenticed', Journal of Education and Work, 19(5), 433-454.

Guile, D (2007) Moebius-strip enterprises and expertise: challenges for lifelong learning, International Journal of Lifelong Education, 26 (3), 241-261. 
Guile, D. \& Okumoto, K. (2007) 'We are trying to reproduce a crafts apprenticeship': from Government Blueprint to workplace generated apprenticeship in the knowledge economy, Journal of Vocational Education and Training, 59(4), 551-575.

Guile, D. \& Okumoto, K. (forthcoming) Developing vocational practice in the jewelry sector through the incubation of a new 'project-object'

Hager, P. (2004) Front-loading, Workplace Learning and Skill Development, Educational Philosophy and Theory, 36 (5), 523-534.

Jensen, K. \& Lahn, L. (2005) The binding role of knowledge: an analysis of nursing students' knowledge ties, Journal of Education and Work, 18(3), 305-320.

KEA European Affairs (2006) The economy of culture in Europe. Available online at: http://ec.europa.eu/culture/eac/sources_info/studies/economy_en.html (accessed 1 March 2007).

Knorr Cetina, K. (1997) Sociality with objects: social relations in postsocial knowledge societies, Theory, Culture and Society, 14 (4), 1-30.

Knorr Cetina, K. (1999) Epistemic communities (Harvard, Harvard Education Press).

Knorr Cetina, K. (2001) Objectual practice, in: T. Schatzki, K. Knorr Cetina \& E. Savigny (Eds.) The practice turn in contemporary theory (London, Routledge).

Knorr Cetina, K. \& Bruegger, U. Global Microstructures; The Virtual Societies of Financial Markets American Journal of Sociology 107 (4), 909-50

Lave, J. \& Wenger, E. (1991) Situated learning: legitimate peripheral participation (New York, Cambridge University Press).

Lundsteen, N. (2007) Paper presented at the Fifth Researching Work and Learning Conference Cape Town, South Africa.

Mansfield, B. \& Mitchell, L. (1996) Towards a competent workforce (Aldershot, Gower).

McDowell, J. (1994) Mind and world (Cambridge, Harvard University Press).

National Committee of Inquiry into Higher Education (NCIHE) (1997) Higher education in the learning society (London, HMSO).

Nerland, M. (2008) Knowledge cultures and the shaping of work-based learning: The case of computer engineering Vocations and Learning, 1(1), pp 49-69

Raffo, C. O’Connor, J. Lovatt, A. and Banks, M. (2000) Attitudes to Formal Business Training amongst Entrepreneurs in the Cultural Industries: situated business learning through 'doing it with others' Journal of Education and Work Vol 13 N0 2 215-230

Schön, D. (1987) Educating the reflective practitioner (San Francisco, Jossey Bass).

Senker, P., \& Senker, J. (1994). Transferring technology and expertise from universities to industry: Britain's Teaching Company Scheme. New Technology, Work and Employment, 9(2), 81-92.

Sennett, R. (2008) The Craftsman (London, Allen Lane).

Sennett, R. (2008 a) Lecture at the Royal Society of the Arts, Monday $11^{\text {th }}$ February.

Sennett. R. Corrosion of Character (London, Allen Lane). 
Thrift, N. (2004) Knowing Capitalism (London, Sage).

UDACE, (1992) Learning outcomes in higher education, UDACE for the Department of Employment

Vygotsky, L, S. (2004) Imagination and Creativity in Childhood, Journal of Russian and East European Psychology, 42(1) 7-297

Winch, C. (2006) Rules, technique, and practical knowledge: a Wittgensteinian exploration of vocational learning, Educational Theory, 56(4), 407-421.

Winch, C. \& Clarke, L. (2004) Front-loaded Vocational Education versus Lifelong Learning: A critique of current UK government policy, Oxford Review of Education, 29(2), 239-252

Wittel, A. (2001) Towards a network sociality, Theory, Culture and Society, 18(1), 55-76. 